\title{
Maytenus comocladiaeformis Reiss. (Celastraceae): redescoberta de uma espécie rara e notas sobre sua distribuição geográfica
}

\author{
Leonardo Biral ${ }^{1,2}$
}

Recebido: 4.03.2010; aceito: 20.09.2012

\begin{abstract}
Maytenus comocladiaeformis Reiss. (Celastraceae): rediscovery of a rare species and notes about its geographical distribution). This note registers the recollection and new data about geographic distribution of Maytenus comocladiaeformis Reissek. The species was known by only two samples, both with little information about its occurrence. The last one was from 1950 and the species was considered extinct.

Key words: Minas Gerais State, recollection, threatened species
\end{abstract}

RESUMO - (Maytenus comocladiaeformis Reiss. (Celastraceae): redescoberta de espécie rara e notas sobre sua distribuição geográfica). Essa nota registra a recoleta e a primeira informação sobre a distribuição de Maytenus comocladiaeformis Reissek. A espécie era conhecida por apenas duas coletas pouco informativas, a última delas de 1950, e era considerada extinta.

Palavras-chave: espécies ameaçadas, Minas Gerais, recoleta

Maytenus comocladiaeformis Reissek, F1. Bras. 11(1): 8, t. I, f. 12. 1861. Tipo. BRASIL. In Brasilia meridionali [Fazenda da Galena], 1836, fl., F. Sellow 2045, 2088 (lectótipo, NY, designado por Carvalho-Okano \& LeitãoFilho(2004); isolectótipos, BR, K, LE, M, US, B [destruído], F neg 13279).

Arbusto; ramos adultos cilíndricos, jovens retangulares, carenados, subalados; folhas subsésseis (pecíolo até $0,3 \mathrm{~cm}$ comp.), elípticas, base obtusa, margens com 3-6 pares de espinhos concentrados na porção distal, ápice agudo com espinho apical, 4,5-6,5 × 1,8-3,0 cm, coriáceas, nervuras secundárias evidentes, impressas; inflorescências fasciculadas, com até quatro flores; frutos não observados e ausentes na descrição original.

Distribuição: Brasil (Minas Gerais). Ocorre em afloramentos calcários no interior de Minas Gerais. Flores em outubro.

Material examinado: BRASIL. MINAS GERAIS: Barão dos Cocais, $19^{\circ} 56^{\prime} \mathrm{S} 4^{\circ} 29^{\prime} \mathrm{W}, 14-\mathrm{X}-2000$, W.A. Teixeira s.n. (BHCB53915, HRCB41406) (figura 1).

De acordo com Carvalho-Okano \& Leitão Filho (2004), Maytenus comocladiaeformis Reissek é conhecida apenas pela coleção-tipo e uma segunda coleta de 1950. A descrição original da espécie foi realizada por Reissek (1861) a partir das coletas 2045 e 2088 (coletas com números diferentes, porém em um único material) de Sellow e seu lectótipo, designado por Carvalho-Okano \& Leitão Filho (2004), encontra-se no herbário do New York Botanical Garden (NY 337409). Entretanto, esse material apresenta uma etiqueta bastante incompleta ("Brasília meridionali fazenda da Galena") que dificulta a obtenção de qualquer informação a respeito do local de coleta. O segundo material citado por Carvalho-Okano \& Leitão Filho (2004) (A. Duarte 2809, RB) também apresenta etiqueta incompleta não sendo possível determinar a cidade do local da coleta, que está caracterizado tão somente como "Fazenda do Dr. Moacyr Novais", proveniente do Estado de Minas Gerais e datado de 19 de julho de 1950.

Mesmo sem apresentar uma informação concreta sobre o local de ocorrência a espécie aparece na Lista Vermelha das Espécies Ameaçadas de Extinção da Flora de Minas Gerais (Mendonça \& Lins 2000) na categoria Provavelmente Extinta (EX) sob alegação de ser conhecida apenas pela coleção-tipo. Quando a

1. Programa de Pós-Graduação em Biologia Vegetal, Universidade Estadual Paulista Júlio de Mesquita Filho, Instituto de Biociências, Departamento de Botânica, Av. 24-A, 1515, 13506-900 Rio Claro, SP, Brasil

2. Autor para correspondência: biral@yahoo.com.br 


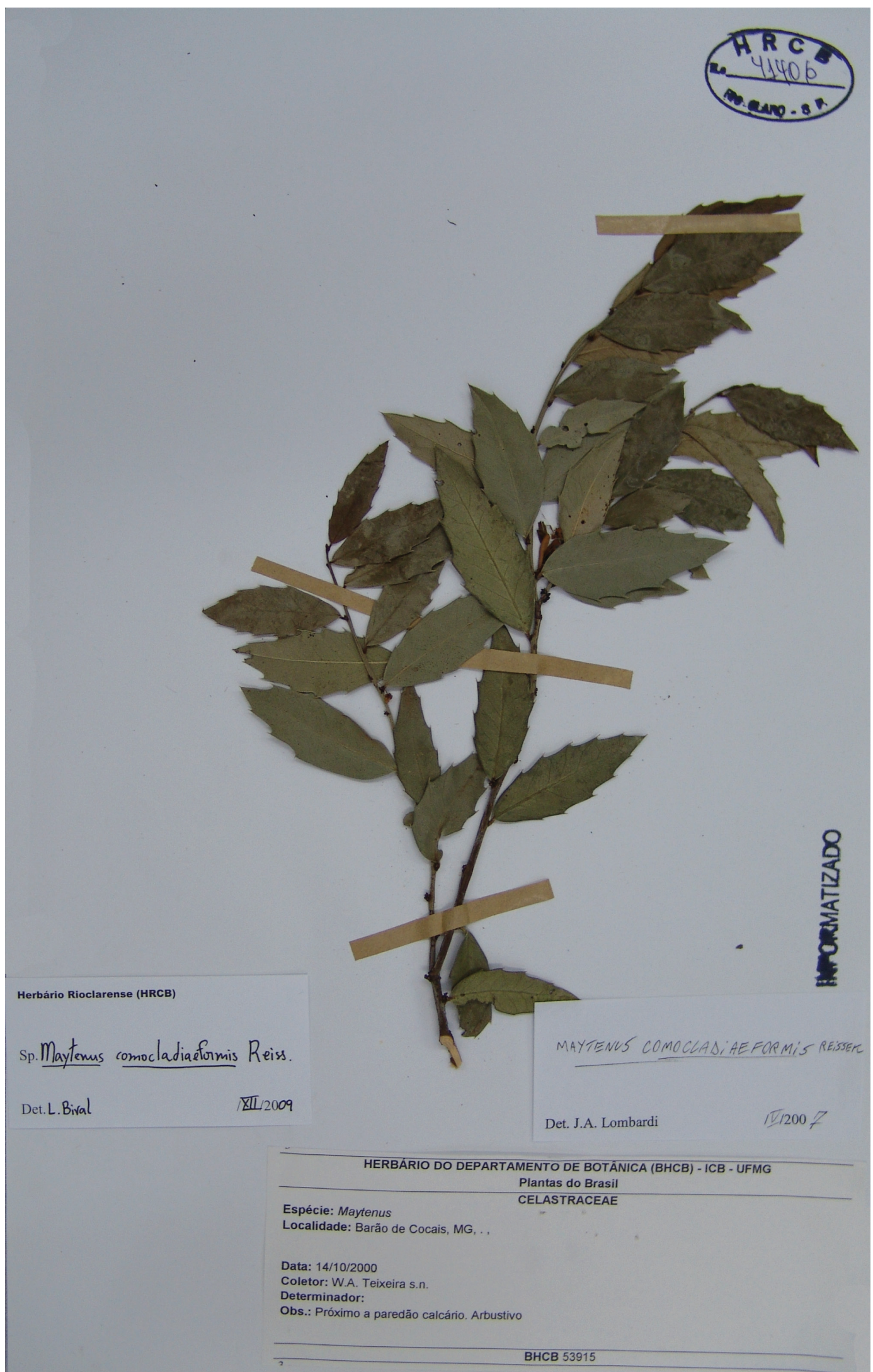

Figura 1. Material examinado de Maytenus clamocladiaeformis Reissek.

Figure 1. Examined specimen of Maytenus clamocladiaeformis Reissek. 
lista foi reavaliada (Drummond et al. 2008) a espécie foi excluída da categoria EX e alocada em Dados Deficientes (DD).

A espécie não aparece em listas de espécies ameaçadas em âmbito nacional, nem tampouco é citada entre as espécies com deficiências de dados (Ministério do Meio Ambiente 2008, Biodiversitas 2010). Provavelmente a informação escassa sobre sua ocorrência não permitiu um enquadramento adequado. Esta nota pretende acrescentar informações a respeito de Maytenus comocladiaeformis, uma espécie pouco conhecida da nossa flora e apresentar a primeira informação precisa sobre sua ocorrência.

Segundo a etiqueta da exsicata examinada, a espécie foi coletada em Barão dos Cocais, Minas Gerais, exatos 50 anos após a última coleta mencionada para a espécie (Carvalho-Okano \& Leitão Filho 2004). Sobre o local de coleta e as observações do espécime, o rótulo apenas informa: "Próximo a paredão calcário. Arbustivo" (figura 2). Esse material representa o primeiro dado exato sobre um local de ocorrência de M. comocladiaeformis. Em razão da coleta recente supõe-se que a espécie seja rara ou ocorra com baixa frequência, porém não esteja extinta como sugerido por Mendonça \& Lins (2000). A localidade da coleta, a cidade de Barão dos Cocais, está localizada no chamado Quadrilátero ferrífero, região de alta diversidade biológica, mas bastante ameaçada por atividades de mineração (Jacobi \& Carmo 2008), e que, portanto, deveria ser alvo de esforços no que diz respeito a coletas botânicas.

No Brasil o gênero Maytenus está representado, no momento, por 45 espécies amplamente distribuídas por todos os domínios fitogeográficos do país (Lombardi et al. 2012). Maytenus comocladiaeformis é caracterizada por apresentar ramos jovens achatados, carenados e subalados e folhas elípticas, subsésseis e com espinhos curtos ao longo de toda a margem foliar. Esses caracteres a distinguem de espécies próximas, como, por exemplo Maytenus quadrangulata (Schrad.) Loes., endêmica da Bahia e que possui folhas pecioladas (pecíolo entre 5 e $6 \mathrm{~mm}$ de comprimento) e maiores (até $14 \mathrm{~cm}$ de comprimento). Os ramos carenados com as arestas conspícuas, subaladas, diferenciam-na de outras espécies com folhas espinescentes que eventualmente possam ser confundidas, tais como Maytenus rigida Martius e Maytenus ilicifolia Mart. ex Reissek.

\section{Agradecimentos}

O autor gostaria de agradecer ao herbário BHCB, aos assessores pelas contribuições ao artigo e a FAPESP (Fundação de Apoio a Pesquisa do Estado de São Paulo) pelo apoio (processo 2011/21879-5).

\section{Literatura citada}

Biodiversitas. 2010. [continuamente atualizada]. Lista de Espécies da Flora Brasileira Ameaçadas de Extinção. Fundação Biodiversitas, Ministério do Meio Ambiente, IBAMA, Sociedade Botânica do Brasil, Rede Brasileira de Jardins Botânicos e Instituto de Pesquisas Jardim Botânico do Rio de Janeiro (acesso em 06.02.2010).

Carvalho-Okano, R.M. \& Leitão Filho, H.F. 2004. O gênero Maytenus Mol. emend. Mol. (Celastraceae) no Brasil extra-amazônico. In: M.S. Reis \& S.R. Silva (eds.). Conservação e uso sustentável de plantas medicinais e aromáticas: Maytenus spp., EspinheiraSanta. Instituto Brasileiro do Meio Ambiente e dos Recursos Naturais Renováveis, Brasília, pp.11-52.

Drummond, G.M., Machado, A.B.M., Martins, C.S., Mendonça, M.P. \& Stehmann, J.R. 2008. Listas vermelhas das espécies da fauna e flora ameaçadas de extinção em Minas Gerais. Fundação Biodiversitas, Belo Horizonte.

Jacobi, C.M. \& Carmo, F.F. 2008. Diversidade dos campos rupestres ferruginosos no Quadrilátero Ferrífero MG. Megadiversidade 4: 25-33.

Lombardi, J.A., Groppo, M. \& Biral, L. 2012. Celastraceae. Lista de Espécies da Flora do Brasil. Jardim Botânico do Rio de Janeiro. http://floradobrasil. jbrj.gov.br/2012/FB006746 (acesso em 04.09.2012).

Mendonça, M.P. \& Lins, L.V. 2000. Lista vermelha das espécies ameaçadas de extinção da flora de Minas Gerais. Fundação Biodiversitas e Fundação Zoo-Botânica de Belo Horizonte, Belo Horizonte.

Ministério do Meio Ambiente. 2008. Lista oficial das espécies da flora brasileira ameaçadas de extinção. Anexo II. Diário Oficial da União, Edição 185, página 75, de 24 de setembro de 2008. Ministério do Meio Ambiente, Brasília.

Reissek, S. 1861. Celastrineae, Ilicineae, Rhamneae. In: C.F.P. Martius \& A.G. Eichler (eds.). Flora Brasiliensis. F. Fleischer, Lipsiae, v.11, pars 1, pp. 1-30. 
